\title{
PRAGMATICS, COGNITION AND ASYMMETRICALLY ACQUIRED EVIDENTIALS ${ }^{1}$
}

\author{
Elly Ifantidou
}

\begin{abstract}
This paper examines the development of a variety of evidential lexical items in Modern Greek from a longitudinal perspective involving 4;6 - 11;7 year olds. The main question to be addressed concerns parallel or asynchronous order of acquisition: Does the ability to use evidentials emerge for all items under investigation synchronically or does such an ability emerge earlier on for certain items while later for others? If the latter holds, how can this developmental lag be explained? An answer to these questions will draw on the pragmatic-cognitive abilities engaged by different types of evidential markers, and in particular, on the complexity of metarepresentations (Sperber 1994; Wilson 2000, 2005) different evidential markers rely on in order to be used by young children.
\end{abstract}

Keywords: Evidentials; Acquisition; Pragmatic sophistication; Conceptual complexity; Metarepresentation

\section{Introduction}

Most studies on the acquisition of evidentials have aimed at earliest occurrences $(2 ; 0-$ 3;3) in children's verbal competence (Wells 1985; Smoczynska 1993; Aksu-Koç 1988; Choi 1995). By contrast, others have emphasized on a late but still underdeveloped evidential capacity at 8 or 12 years (Piéraut-Le Bonniec 1980; Perkins 1983; Coates 1988; Booth and Hall 1995; Bascelli and Barbieri 2002). Despite the contradictory picture emerging from early competencies and late shortcomings in children's ability to use evidentials (e.g. the case of modals), no systematic attempt has been made to reconcile the findings. Notwithstanding occasional reference to more conceptually demanding as opposed to less conceptually demanding lexical items (Booth and Hall 1995, on cognitive verbs), or acknowledgment of explicit links between linguistic and conceptual capacities affecting acquisition (Papafragou 1998, 2001, on modals), no unified explanatory answer on pragmatic and cognitive grounds has yet been provided for the prolonged and asymmetrical development of evidential markers.

The issue to be addressed in this paper is: Why are certain types of evidentials, such as modals or 'mental state' verbs, reliably used or interpreted by preschool children, whereas adverbials, syntactically more complex evidential expressions or

1 I wish to thank the Pragmatics anonymous reviewer for detailed comments and suggestions, Chryssoula Lascaratou for valuable input on related syntactic issues as well as the children and their teachers on whose willing participation this research largely relied on. 
particles are not until school years? Within the same category, why are verbs such as know or think appropriately used by preschool children, whereas suppose is not? These are questions that have hardly been raised, let alone answered in the developmental literature.

I believe that examining the development of a variety of evidential items for a wide range of children (4-12 year-olds) may offer useful insights into whether asymmetries occur or not, and if so, into why they do. An explanation will draw on how asymmetries and generally order of acquisition may help track down correlations with stages in cognitive growth. Linking stages of linguistic competence to stages of cognitive growth can show how stages in cognitive growth may predict or even guarantee, stages in the acquisition of lexical items. And this could be an explanation in its own right for why certain evidentials are acquired earlier than others.

Most authors agree that evidentials have two main functions: They indicate the source of information (observation/hearsay/inference/memory), and the speaker's degree of certainty or commitment to the information conveyed (weak/strong) (for examples and references, see Ifantidou 2001: 1-8). For this study, a variety of evidential lexical items has been used to trace differentiating semantic/stylistic, pragmatic or cognitive factors affecting acquisition. Three verbs, the commonly

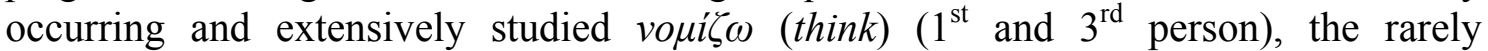

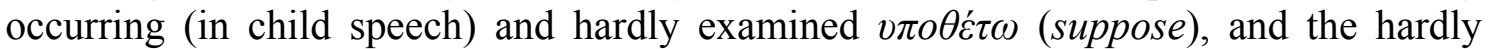
occurring (in child speech) $\theta \alpha \rho \rho \omega ́$ (ween) (literary form of think), the syntactically

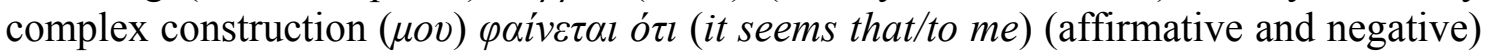
and three adverbials $\pi \rho \circ \varphi \alpha v \omega ́ \varsigma$ (evidently), $\alpha \sigma \varphi \alpha \lambda \omega ́ \varsigma$ (certainly), $\pi \imath \theta \alpha \nu \omega ́ \varsigma$ (possibly) have been tested in story reading and comprehension activities run in the form of interviews for the younger children and in the form of written tasks for the older ones. The evidentials have been selected on the basis of contrasting patterns along the lines of frequent vs. less frequent occurrence (think vs. suppose vs. ween $)^{2}$, syntactic complexity (main-clause construction it seems that vs. parenthetical I think) ${ }^{3}$ and semantic/stylistic complexity (informal think vs. poetic ween). Results will be contrasted with previous findings on Modern Greek hearsay particles $\tau \dot{\alpha} \chi \alpha / \delta \dot{\eta} \theta \varepsilon v$ (supposedly/as if) (Ifantidou $2005 \mathrm{a}, 2005 \mathrm{~b}$ ) in terms of syntactic complexity (main-clause construction it seems that vs. parenthetical taha/dithen $)^{4}$ and pragmatic complexity (think vs. taha/dithen $)^{5}$.

The intriguing question is: What may possibly trigger an earlier, and possibly easier, acquisition for certain types of evidentials but a later, and possibly more

${ }^{2}$ As in Modern Greek natural child-speech corpus (see Ifantidou 2005c. Paper delivered at the $9^{\text {th }}$ IPrA Conference, Riva del Garda, Italy; to appear in C. Paradis and L. Ekberg (eds.) Evidentiality: theoretical and applied).

${ }^{3}$ Constructions consisting of a main clause and a subordinate/complement clause (e.g. I think that/it seems that John is coming) are syntactically complex; hence the movement or extraction of any elements out of such a complex syntactic construction is barred. Genuine parenthetical constructions, however, (e.g. John is coming, I think/it seems) are syntactically less complex since they are syntactically independent of their host clauses, and hence they escape a variety of syntactic constraints, such as relative clause island, wh-island, complex NP constraint (e.g. Who do you think that/does it seem that is coming vs. who, do you think/does it seem, is coming) (for analysis and references, see Ifantidou 2001: 132-134).

${ }^{4}$ Taha/dithen are genuine parenthetical particles, and as such, are considered as syntactically less complex (see footnote 2): They can freely move in the sentence, i.e. they can modify the whole clause by occurring either in the beginning or in the middle or at the end of the sentence (e.g. taha, they were innocent/they were, taha, innocent/they were innocent, taha) (see Ifantidou 2005a, 2005b).

5 Taha/dithen are considered to be pragmatically complex evidentials on the assumption that they are standardly used to communicate hearsay information ironically intended (see Ifantidou 2005a). 
effortful, acquisition for other types? Frequency in natural language input, syntactic or semantic complexity, pragmatic or cognitive sophistication, or a combination of these are a few plausible factors affecting acquisition. The working hypothesis here is that pragmatic-cognitive sophistication required for a fully-fledged communicative ability of certain evidentials delays their acquisition. Evidential items requiring simpler pragmatic-cognitive inferencing are easier to acquire and as a consequence, are reliably used at early ages. Simpler or more complex inferencing is, for the purposes of this work, a matter of more or less complex metarepresentations involved in understanding evidential items (Sperber 1994). I will show that the fewer the layers of metarepresentation required, the easier and earlier for evidentials are acquired, whereas the more the layers of metarepresentation required, the harder and later for evidentials are acquired.

\section{Evidentials and order of acquisition}

Research on the acquisition of evidentials has been selectively directed at modals (can, must, may) (Hirst and Weil 1982; Stephany 1986; Byrnes and Duff 1989; Noveck, Ho and Sera 1996; Bascelli and Barbieri 2002) or at cognition verbs (think, know, guess) (Johnson and Maratsos 1977; Johnson and Wellman 1980; Bretherton and Beeghly 1982; Shatz, Wellman and Silber 1983; Booth and Hall 1995; Schwanenflugel, Fabricius and Noyes 1996). Interestingly, other types of evidential markers, such as adverbials (evidently, obviously, allegedly) or more complex syntactic constructions (it appears that, it seems that/to me, she is reported to, he is supposed to) or verbs other than think or know (suppose, suspect) have been sidetracked in developmental research. Presumably, modals and 'mental state' verbs provide straightforward evidence for earliest occurrences in child speech, whereas adverbials and syntactically more complex evidential markers do not. Notwithstanding the importance of assessing the occurrence of modals or 'mental state' verbs in early child speech, other types of evidentials may be worth examining too for they may offer further insights into children's developing mind. In fact, the more complex the pragmatics of evidentials, the more intriguing their development seems to be, and so does the issue of accounting for what these evidentials may rest on in order to be acquired.

Research on evidential verbs - referred to as 'cognitive' or 'mental state' verbs suggests that children acquire the commonest of these between $2-4$ years of age (Johnson and Wellman 1980; Miscione et al. 1978; Shatz, Wellman and Silber 1983; Moore, Bryant and Furrow 1989; Moore and Davidge 1989; Moore, Pure and Furrow 1990; Astington and Jenkins 1995). Shatz, Wellman and Silber (1983: 311) report first evidential uses of know and think at 2;4 (see also Bretherton and Beeghly 1982: 914). Evidence for a clear-cut distinction between know and think occurs at 4 when children are shown to distinguish between the implications of know (as presupposing truth) and think (as implicating the possibility of falsity): Children correctly judge the character who hides the object as knowing (not thinking) the truth, i.e. knowing that the hidden toy is under box B, but the character who seeks the object as thinking (not knowing) what is false, i.e. thinking that the hidden toy is under box A (Johnson and Maratsos 1977). And although at 4 children lack refined semantic differences between know and guess, they appropriately use them to modify the reliability of statements (Johnson and Wellman 1980). By 4, the presuppositions of know and think - namely, that know 
presupposes the truth of its complement whereas think does not - are acquired, whereas at 7 the presuppositions of believe ${ }^{6}$ are not as yet (Abbeduto and Rosenberg 1985). Bassano's study (1983) confirmed the 4 and 5-year-olds' understanding of savoir $(80 \%$ correctly attributed the utterance "I know that I have a fish" to the doll who has a fish in its box and can see it). The same children showed a less clear-cut interpretation of croire ( $40 \%$ correctly attributed the utterance "I think I have a fish" to the blindfolded dolls). Worth mentioning is children's difficulty with the negation of know: Only 45\% correctly attributed the utterance "I know that I do not have a fish" to the doll who had a bird and could see it, and only $40 \%$ correctly attributed the utterance "I do not know if I have a fish" to the blindfolded dolls (vs. 80\% for the respective affirmative). Such differences between affirmative vs. negative evidentials may be worth more consideration than standardly assumed. In section 4, the issue of pursuing negation as another factor possibly affecting the lexical acquisition of evidentials is raised.

Later work on the development of know and think was based on an explicit distinction between semantic vs. pragmatic uses (Frank and Hall 1991). Frank and Hall excluded 'pragmatic' uses, i.e. conversational fillers, rhetorical/exam questions, to focus exclusively on semantic meanings. This is how the authors distinguished between the two:

Semantic utterances were those in which the literal internal state meaning of know contributed directly to the intended meaning of those utterances. Pragmatic utterances were those in which the literal internal state meaning of know did not contribute directly to the intended meaning of those utterances. (Frank and Hall 1991: 289)

It is not clear what the authors mean by "direct contribution to the intended meaning of an utterance". If, as claimed, they are interested in semantic meaning, then they must mean 'contribution to the truth conditional meaning of the utterance'. But surely the semantic contribution of lexical items cannot preclude their pragmatic contribution. For example, I know may contribute to the truth conditions of the utterance containing it, as in 'I know that Susan has won the elections', or it may not contribute to the truth conditions of the utterance containing it, as in 'Susan has won the elections, I know', without this affecting its pragmatic function as a strengthening evidential marker in either case. Similarly, I think may contribute to the truth conditions of the utterance containing it, as in 'I think that Susan has won the elections', or it may not contribute to the truth conditions of the utterance containing it, as in 'Susan has won the elections, I think', without this affecting its pragmatic function as a weakening evidential marker in either case (Ifantidou 2001). If 'pragmatic use' has been loosely used by Frank and Hall to refer to 'conversational fillers', such as I think so, I guess so, which would be one way of delimiting the data, then this does not become clear from either their definition or their examples. For example, conversational fillers may have a pragmatic function that needs to be considered too, as in Peter's reply to Mary - e.g. Mary: I think so, Peter: I know so. Overall, a semantic/pragmatic distinction may be misleading for the following reasons. Firstly, excluding 'pragmatic' uses on the basis of hazy distinctions runs the risk of ruling out part of relevant data. Secondly, child understanding and child use does not rely on selectively drawing on the semantic meaning of lexical items. A full appreciation of the developmental trajectory of evidentials requires consideration of

${ }^{6}$ Believe does not normally presuppose the truth of its complement but it may do so if the speaker calls upon faith rather than evidence. 
pragmatic uses too (with the exception of genuine conversational fillers such as you know) since pragmatic uses may depend on the semantic meaning of the lexical items in question, or vice versa (Moore, Bryant and Furrow 1989: 170).

Another problem with Frank and Hall's account, which carries over to Booth and Hall (1995), concerns the hierarchization of cognitive verbs into levels of meaning, with apparently increasing difficulty of acquisition (ibid.: 533) and descending frequency of use (ibid.: 541) from perceptual types (e.g. hear, see) to cognitive types (e.g. know, guess). A careful look at the six levels of meaning, namely:

1. Perception: The speaker reports the act of perception (e.g., "I heard your story").

2. Recognition: The speaker acknowledges familiarity with some person or concept (e.g., "I know that face").

3. Recall: The speaker refers to factual information that he or she remembers (e.g., "I know his phone number").

4. Understanding: The speaker refers to a conceptual framework or reasoning (e.g., "I know why he did that").

5. Metacognition: The speaker focuses on discussing the awareness of mental acts (e.g., "Pretending can be fun").

6. Evaluation: The speaker refers to attitudes and beliefs about the truth of statements (e.g., "He guessed the answer, but I know it"). (Booth and Hall 1995: 532).

shows that all refer to essentially evidential functions: They either indicate the source of knowledge (observation, hearsay, memory) - levels 1,3 - or indicate the speaker's degree of certainty - levels $2,4,6$. And even though the specific metacognition example in 5 does not include an evidential verb, other examples the authors cite under this category do, e.g. "I would like to know more than I do", "I am thinking about it" (Frank and Hall 1991: 290, 295).

Despite the unclear boundaries between overlapping levels (as suggested above, 1, 2, 3 and 4 seem to straightforwardly fit under 6 - the overarching evidential category), some interesting indications as to the acquisition of evidentials were obtained. First, the hierarchy of evidentials in terms of increasing difficulty (from level 1 to level 6) correlating with falling frequency of occurrence was not quite borne out by the data. As expected, children used "evaluation" know and think proportionately less compared to all other categories except for "perception". However, Frank and Hall's 1991 study revealed an unexpected preference specifically for "evaluation" think that exceeded all other levels. Booth and Hall's 1995 study dealt specifically with know, still percentages for children's comprehension of know disrupted the suggested ' $1 \rightarrow 6$ ' hierarchy of categories for all ages. For example, 6- and 9-year olds used know to refer mostly to an act of "understanding", whereas 12-year-olds used know to refer mostly to an act of "recognition". These results are interesting because they suggest that the developmental trajectory of evidentials does not necessarily follow a hierarchy from "concrete" to more "abstract", or from "lower levels" $(1-4)$ to "higher levels" $(5-6)$ (Booth and Hall 1995: 531, 533, 541). Moreover, it is not clear why "evaluation" know, as in (a)

(a) Tester: How come Jackie does not know (who will win the race to the pool)? Answer: She may have a good idea but she doesn't know for sure.

is more "conceptually demanding" than "metacognition" know, as in (b):

(b) Tester: How does Maria know (that she must ask Jackie in order to actually race her?) 
Answer: First she pretends, then she asks to race. (Booth and Hall 1995: 532, 549).

The two uses of know seem to be equally demanding in cognitive effort, because in both examples the child has to provide an answer by interpreting Jackie's and Maria's thoughts respectively. Similarly, it is not clear why "evaluation" know - e.g. "He guessed the answer, but I know it" - is of "increased conceptual difficulty" compared to "understanding" know - e.g. "I know why he did that". If there is an issue of "conceptual demands" or "increasing conceptual difficulty" incurred by evidential items, we ought to be able to specify exactly how this is determined and show how it affects their order of acquisition.

In fact, most of the studies referred to above focused on how the semantics of cognitive verbs is acquired, rather than on how children draw on the pragmatics of cognitive verbs to use them. Moore, Bryant and Furrow (1989) and Moore, Pure and Furrow (1990) were the first to conduct experimental work on specifically testing children's use of mental verbs and modals to indicate degrees of speaker certainty. As already suggested, it is not at all clear if children need have fully mastered the semantic nuances (entailments, presuppositions, implications) of these verbs in order to be able to appropriately use them as evidential markers. As Moore, Bryant and Furrow point out:

Children's understanding of the pragmatic function of marking relative certainty might be based on the semantic understanding of the properties of factive and nonfactive mental verbs. However, the opposite is equally possible. (1989: 170)

Their work suggests that by 4 years of age children distinguish between know vs. think, between know vs. guess, and between know vs. think/guess, with know expressing certainty and think/guess expressing uncertainty. Moore, Pure and Furrow obtained similar results with modals: Between 3-4 years of age, children mastered degrees of certainty as encoded by the must-might, must-could, probably-maybe contrasts, whereas by 5-6 years of age, understanding of the probably-possibly contrast had considerably improved. Further contrasts between pairs of modals expressing uncertainty, e.g. possibly vs. maybe, could vs. might, were shaky at 5-6 years of age, but granting adults' lack of unanimity on these, children's reaction may not be too surprising.

Despite extensive experimental work on the comprehension of 'mental' state verbs, the use of these terms in children's spontaneous speech has been marginally studied. Interestingly, the results obtained so far (Shatz, Wellman and Silber 1983; Bretherton and Beeghly 1982; Bloom et al. 1988) pull us to a different direction. First uses to indicate the speaker's degree of certainty ("modulation of assertion") occur between 2;4 - 2;8 (Bretherton and Beeghly 1982; Shatz, Wellman and Silber 1983). These results were confirmed by further work on children's spontaneous speech by Bloom et al. 1988, who showed that children between $2-3$ years of age use think and know to specifically modify speaker's degree of commitment to the complement clause. Think expressed uncertainty, and this was backed up by a number of observations, e.g. think largely drew on prior discourse, indicating that the children were not yet fully committed to the truth of the information (in the prior discourse), it co-occurred with modals in complement position (indicating uncertainty) but hardly with complementizer 'that' (indicating certainty when complementing think). Know, on the other hand, was less used to refer to prior discourse but mostly to introduce new discourse initiated by the child herself (ibid. 118). The authors concluded by suggesting that children's ability 
to "modify the reliability of statements" by know and think precedes the acquisition of their "truly cognitive meanings" (ibid. 119). Which seems to further question the role of a rigid semantic/pragmatic distinction in studies of early lexical development and more importantly, to redirect emphasis on their pragmatic use. The developmental evidence presented in the next section rests on the assumption that children draw on their conflated semantic/pragmatic knowledge of evidential lexical items to assess their meaning/use.

\section{Experimental evidence}

\subsection{Method and design}

\section{Rationale}

This study examines 4;6 - 11;7 year-old children's understanding of seven evidential items. Evidentials were tested in the context of twelve different extracts selected from seven stories appearing in children's illustrated readers. The stories and respective extracts were selected on the basis of the following criteria: Firstly, evidential items had to occur originally in non-adapted children's narratives, secondly, the relevant scenes had to be illustrated originally by coloured drawings, and thirdly, where the same evidential item was tested more than once, the context of occurrence had to vary. For example, think was tested in four different extracts/contexts: (a) speaker's thought concerning hearsay knowledge (Linguistic task $1^{7}$ ), (b) speaker's thought concerning hearer's thought (Linguistic task 5), (c) writer's inference of a character's thought $\left(3^{\text {rd }}\right.$ person narrative preceded by guess) (Linguistic task 3) and (d) speaker's thought concerning his own state of being (Linguistic task 9). Similarly, it seems (that/to me) was tested in three different extracts/contexts: (a) speaker's own first-hand knowledge (Linguistic task 2), (b) inference drawn on observed (other's) behaviour (Linguistic task 4) and (c) inference drawn on facts (Linguistic task 6). Different contexts and functions were purposely chosen to encourage children's use of their semantic/pragmatic resources in interpreting the evidential item in question. Each story was read aloud from the beginning to the end to ensure a better understanding of the plot, the setting, the circumstances and the characters involved. Stories were chosen for including more than one occurrence of evidential items in an attempt to reduce the number of stories children would have to be familiarized with through reading sessions. Thus, twelve forms of seven evidential items were tested in the context provided by seven stories. Table 1 presents the testing order of evidentials/linguistic tasks and the respective sources they originally appear in.

\footnotetext{
${ }^{7}$ For Linguistic tasks $1-12$, see Appendix.
} 


\begin{tabular}{|c|c|c|}
\hline 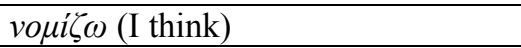 & 1 & Bananas in pyjamas: Invitation to dinner \\
\hline$\mu o v \varphi \alpha ́ v \eta \kappa \varepsilon$ (it seemed to me) & 2 & The two friends \\
\hline 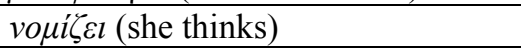 & 3 & What's that shape? \\
\hline 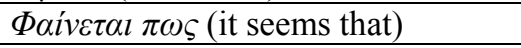 & 4 & What's that shape? \\
\hline 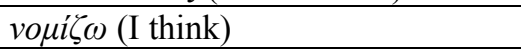 & 5 & Bananas in pyjamas: an amazing toy \\
\hline 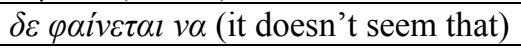 & 6 & A piece of cake \\
\hline$Y \pi o \theta \varepsilon \dot{\varepsilon} \tau($ I suppose) & 7 & Pinnochio in Athens \\
\hline$\pi \rho o \varphi \alpha \nu \omega ́ \varsigma$ (evidently) & 8 & Bananas in pyjamas: an amazing toy \\
\hline 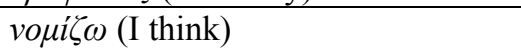 & 9 & Pinnochio in Athens \\
\hline$\pi \imath \theta \alpha v \omega ́ \varsigma$ (possibly) & 10 & Bananas in pyjamas: an amazing toy \\
\hline$\theta \alpha \rho \rho \omega ́$ (I ween) & 11 & Pinnochio in Athens \\
\hline$A \sigma \varphi \alpha \lambda \omega ́ \varsigma$ (certainly) & 12 & The shapes \\
\hline
\end{tabular}

Table 1: Evidentials, linguistics tasks and readers (for references, see Appendix) in testing order.

Evidential items were tested in assumed ascending levels of difficulty so that children were not initially discouraged by effortful answers. Feedback was not provided during the testing session because of the facilitating effect this would have on items tested more than once. Coloured drawings were attached to all extracts, followed by an openended question format (see Appendix). The order of activities was counterbalanced by successively alternating evidential categories (Table 1).

\section{Participants}

Participants were 291 children recruited from two urban kindergartens in Athens, $3^{\text {rd }}$ nursery of N. Smyrni and $6^{\text {th }}$ nursery of Pireas, and two primary schools in Athens, $3^{\text {rd }}$ and $16^{\text {th }}$ primary schools of Ilioupoli, serving middle-class families. In particular, the primary school children were twenty one 6-year-olds (range $=5 ; 5-6 ; 7$ ), thirty two 7year-olds (range $=6 ; 4-7 ; 10$ ), sixty one 8 -year-olds (range $=7 ; 2-8 ; 1$ ), thirty seven 9year-olds (range $=8 ; 6-9 ; 10$ ), fourty six 10-year-olds (range $=9 ; 6-10 ; 3$ ) and fifty three 11 -year-olds $(10 ; 6-11 ; 7)$. The nursery children were twenty prenursery 4-year-olds (range $4 ; 6-5 ; 6$ ) and twenty one nursery 5 -year-olds (range $5 ; 7-6 ; 2$ ). Thirty $4^{\text {th }}$ semester undergraduates of the English Department served as the piloting group for monitoring questions and expected answers. All children were monolingual, native speakers of modern Greek, except for two bi-lingual girls, who were excluded from analysis. The groups included approximately equal numbers of boys and girls.

\section{Instruments of assessment}

Linguistic tasks handed out to primary school 6-12 year-old children came with coloured drawings of the scene described in the narrative. Each linguistic extract fitted in an A4 sheet of paper which included a $0,20 \mathrm{~cm} \times 0,20 \mathrm{~cm}$ size coloured drawing. The scene depicted in the drawing helped to infer the correct answer but provided no clearcut indication of the intended interpretation of the evidential item in question. Linguistic tasks run with the younger 4-5 year olds were read out and the respective coloured drawings were simultaneously shown by the experimenter. All drawings were extracted and reproduced from the original story books. Linguistic tasks were handed out to 6-7 year-old primary school beginners after a lapse of five-month schooling, in order for children to be able to handle the linguistic tasks on their own.

\section{Procedure}

Linguistic tasks were run as classwork at school. Reading sessions on different days 
served children's familiarization with every story. Each story was read out in class by the teacher. Children were told that at the end of the seven reading sessions, they would have to answer short questions on the meaning of words used in the stories. On the day after the last story was heard, each child received her/his answer sheet, which included twelve drawings and twelve extracts to allow individual access to the evidential item in question and its linguistic context. Linguistic tasks were handed out to primary school children of the six grades and were completed in class while the children were supervised by their teachers. Linguistic tasks were read out individually to the younger 4-5 year olds while the relevant coloured drawings were shown by the experimenter. For the prenursery and nursery children, questions were sometimes rephrased (see Appendix) or enacted to enhance children's concentration and facilitate their uptake. All questions were presented in an open-ended format, with two possible interpretations provided and a third open option, to be specified by the child if $\mathrm{s} / \mathrm{he}$ wished to. The order of questions was counterbalanced by successively alternating the three options (see Appendix). Nursery children were tested individually in quiet areas of their kindergartens by the author herself. Each session lasted a total of 15 minutes.

\subsection{Results and discussion}

Evidential

\begin{tabular}{|c|c|c|c|}
\hline & & & \\
\hline I think & 1 & $71,42 \%$ & $28,57 \%$ \\
\hline it seemed to me & 2 & $55,23 \%$ & $44,77 \%$ \\
\hline he thinks & 3 & $51,42 \%$ & $58,57 \%$ \\
\hline it seems that & 4 & $42,63 \%$ & $57,37 \%$ \\
\hline I think & 5 & $71,42 \%$ & $28,57 \%$ \\
\hline it doesn't seem that & 6 & $71,42 \%$ & $28,57 \%$ \\
\hline I suppose & 7 & $62,85 \%$ & $37,14 \%$ \\
\hline evidently & 8 & $28,57 \%$ & $71,42 \%$ \\
\hline I think & 9 & $64,28 \%$ & $35,71 \%$ \\
\hline Possibly & 10 & $35,71 \%$ & $64,28 \%$ \\
\hline I ween (literary) & 11 & $64,28 \%$ & $35,71 \%$ \\
\hline Certainly & 12 & $35,71 \%$ & $64,28 \%$ \\
\hline
\end{tabular}

Table 2: Percentages of evidential interpretation by prenursery/ 4-5 year-old passers $(\sqrt{ })$ and failers $(\mathbf{X})$. Number of subjects: 20.

\begin{tabular}{|l|l|l|l|}
\multicolumn{4}{|c|}{ } \\
\hline I think & 1 & $61,90 \%$ & $38,09 \%$ \\
\hline it seemed to me & 2 & $71,28 \%$ & $28,72 \%$ \\
\hline he thinks & 3 & $66,66 \%$ & $33,33 \%$ \\
\hline it seems that & 4 & $38,09 \%$ & $61,90 \%$ \\
\hline I think & 4 & $80 \%$ & $20 \%$ \\
\hline it doesn't seem that & 5 & $63,42 \%$ & $36,58 \%$ \\
\hline I suppose & 6 & $68,57 \%$ & $31,42 \%$ \\
\hline evidently & 7 & $23,42 \%$ & $76,58 \%$ \\
\hline I think & 8 & $74,32 \%$ & $25,68 \%$ \\
\hline Possibly & 9 & $13,45 \%$ & $86,55 \%$ \\
\hline I think (literary) & 10 & $67,34 \%$ & $32,66 \%$ \\
\hline Certainly & 11 & $28,15 \%$ & $71,85 \%$ \\
\hline
\end{tabular}

Table 3: Percentages of evidential interpretation by nursery/ 5-6 year-old passers $(\sqrt{ })$ and failers $(\boldsymbol{X})$. Number of subjects: 21. 
Prenursery children exhibited a clear-cut confidence in interpreting think regardless of context. The same children showed a clear-cut difficulty in interpreting the adverbials possibly, evidently, certainly. Given previous findings on early use of think and the elusiveness of evidential adverbials in the developmental literature (section 2), both results were quite expected. A considerable number scored rather poorly in the case of affirmative it seems that, but scored quite successfully in the case of negative it does not seem that, which were both unexpected results. The children's reaction is quite puzzling because both the affirmative and the negative forms are quite commonly used evidential items ${ }^{8}$. Equally surprising was their correct interpretation of poetic ween.

A possible misleading factor in the case of it seems that is the literal meaning of fenete $=$ 'can be seen'/de fenete $=$ 'cannot be seen' in Modern Greek, which may have led children to mistakenly consider it as a 'certainty' marker in the affirmative ('seeing makes one certain') and to correctly consider it as an 'uncertainty' marker in the negative ('not seeing makes one uncertain'). A possible explanation of children's ability to interpret the uncommon poetic form of think is the linguistic preceding context (as underlined below) priming a weakening evidential reading:

Mouse: “I'm ashamed to say this, but, you see, my mouth waters. Can I have a candy?" he asked impatiently.

Snail Gary: "The candies are for Pinocchio" Snail Gary explained, "but I ween they are enough for you and fifty more clockwork mice to eat".

The underlined assertion raises the implication 'you cannot have a candy' which is next, however, contradicted and eliminated by the conjunction 'but'.

These results seem to suggest that children rely on a combination of semantic/pragmatic meaning when interpreting the evidentials in question. In the case of the commonly occurring and semantically/stylistically unmarked it seems that, purely semantic knowledge - i.e. fenete/'it can be seen' in Modern Greek - interfered with the pragmatic function of a weakening evidential marker resulting in the wrong answer. In the case of it does not seem that, purely semantic knowledge - de fenete/'it can not be seen' in Modern Greek - interfered with the pragmatic function of the same weakening evidential marker resulting in the correct answer. Which means that in the latter case, children answered correctly for the wrong reasons. In the case of the rarely occurring and semantically/stylistically marked ween, the pragmatic function of a weakening evidential marker was enhanced by the context and hence triggered the correct interpretation despite children's lack of knowledge of the verb's semantic meaning. Similarly, in the case of the hardly occurring suppose (footnote 8), its pragmatic function as a weakening evidential marker was primed by the preceding context (knowing who Pinnochio is - an Italian newcomer in Athens - King Snail assumes that he has not visited Akropolis before; Appendix, Linguistic task 7) to trigger the correct interpretation, regardless of children's loose grasp of the verb's semantic meaning. These indications confirm reservations (section 2) about developmental studies on

\footnotetext{
${ }^{8}$ In children's natural language speech, it seems/does not seem that/to me occurrences amount to $56 \%$, certainly occurrences amount to $55,5 \%$ and possibly occurrences amount to $59 \%$ contrasted with zero occurrences of suppose (Modern Greek child language corpus, Ifantidou 2005c. Paper delivered at the $9^{\text {th }}$ IPrA Conference, Riva del Garda, Italy; to appear in C. Paradis and L. Ekberg (eds.) Evidentiality: theoretical and applied).
} 
evidentials conducted along the lines of a rigid distinction between 'semantic meaning' vs. 'pragmatic use'. Children seem to be drawing on any resources available, whether semantic or pragmatic, when processing incoming lexical items ${ }^{9}$, especially where new lexical items are presented, as in the case of ween or evidently. It would be interesting to identify the factors that help them succeed or cause them to fail in doing so. The results so far show that children are flexible at relying on either semantic or pragmatic aspects of the interpretation process depending on which one they can (less effortfully) have access to. Only when their semantic and pragmatic knowledge level off can children reliably retrieve the intended interpretation.

Worth mentioning is children's interpretation of the various occurrences of think. Children provided easier, relatively straightforward answers for $1^{\text {st }}$ person think (Linguistic task 1) compared with shaky, more effortful answers for $3^{\text {rd }}$ person think (Linguistic task 3). Even more intriguing is the close parallel between think and suppose: think was only marginally better received than suppose, which, given the frequent occurrence of think (as standardly reported in the developmental literature, (section 2) and the absence of suppose in child-speech (Ifantidou 2005c), contradicts anticipated results. Finally, suppose was by far better received than evidently, possibly, certainly. The question is: Why do these differences in children's interpretative abilities of evidentials occur?

A first observation towards an explanation concerns the distinction between facilitating $1^{\text {st }}$ person verbs vs. $3^{\text {rd }}$ person verbs or adverbials. Children seemed to generally tune in quickly with $1^{\text {st }}$ person evidential verbs - even where the items were less familiar, e.g. suppose, ween. Consequently, children willingly risked an answer on pragmatic grounds and were mostly successful. On the contrary, children were genuinely puzzled with adverbials evidently, possibly, certainly, and less so with $3^{\text {rd }}$ person think. Table 4 presents scoring mean percentages in descending order.

\begin{tabular}{|l|l|l|}
\hline Succeeding in interpreting & I think & $67,67 \%$ \\
\hline & it does not seem that & $67,42 \%$ \\
\hline & I ween & $65,81 \%$ \\
\hline & I suppose & $65,71 \%$ \\
\hline & it seemed to me & $63,25 \%$ \\
\hline & she thinks & $59,04 \%$ \\
\hline Failing in interpreting & it seems that & $40,36 \%$ \\
\hline & evidently, possibly, certainly & $36,13 \%$ \\
\hline
\end{tabular}

Table 4: Mean percentages of tested evidentials in descending order of successful interpretation by prenursery and nursery children. Number of subjects: 41.

These findings seem to suggest that the less the source of information was explicitly stated, the more children risked their answers, and the more they ended up with the wrong ones. For example, children showed more confidence with it seems to me than with it seems that. This trend peaked with adverbials, where it is not clear who the source of the information provided is, i.e. 'whom is it evident to', 'whom is it possible to', 'whom is it certain to', in which case the hearer, or reader, has to infer it. The next question then is: Does inferential processing affect the interpretation of evidentials in any significant way?

${ }^{9}$ The assumption being that in natural-language production too children use the evidentials in question guided by a similar holistic approach to lexical meaning with syntactic/semantic/pragmatic/ stylistic/prosodic features contributing to the way words are used. 
Identifying the source of information is one of the functions evidentials may have. Retrieving (for hearers) or encoding (for speakers) one's own or other's beliefs (in the form of utterances of thoughts) with varying degrees of certainty is another function that evidentials typically serve. What seems to have been underestimated in the developmental literature is that both can be highly inferential processes, engaging the speaker or the hearer in different levels of representational complexity. Table 5 shows how evidentials may get increasingly more sophisticated.

(1) Pinnochio: I think I'm falling asleep.

(2) It's the first time, I suppose, you're visiting Athens.

(3) The triangle has, certainly, three angles. (on seeing the bear leaning over the Bunny)

(4) Ferret: It seems to me that I've seen the bear whispering in your ear.

(5) Banana 1: I think he said he is a cart.

(6) Banana 1: I think I am thinking what you're thinking.

(7) Efi thinks she knows.

(8) It seems the baby likes Sarah's new toy boat.

(9) It doesn't seem that we've lost any weight, dear.

(10) Evidently it doesn't look like a slide, it looks like a see-saw, Eimy said.

(11) You possibly made a bed, Loulou said.

Table 5: Tested evidentials in increasing order of pragmatic sophistication.

The utterances in $(1-3)$ involve two levels of representation: They represent the speaker's thought about his own state of being (1), and the speaker's belief about a state of affairs $(2,3)$. The utterances in $(4-11)$ involve three levels of representation: (4) represents the speaker's belief about his first-hand (visual) information regarding a state of affairs. (5) represents the speaker's thought about another's utterance regarding a state of affairs. (6) represents the speaker's thought about his own thought regarding the hearer's thought. (7) represents the writer's belief about Efi's thought regarding Efi's own belief. (8) represents the writer's thought about another's (baby) desire regarding a state of affairs. (9) represents the speaker's (father-elephant) dissociative attitude regarding the hearer's (mother-elephant) belief regarding a state of affairs (losing weight through dieting). (10) represents the speaker's belief about her own dissociative thought regarding a state of affairs. (11) represents the speaker's dissociative thought about the hearer's thought regarding a state of affairs.

A comparison of Tables 4 and 5 shows that the two run parallel except for two incompatibilities. Firstly, (3) involves two levels of representation, yet children failed to correctly interpret the evidential function of certainly as a strengthening marker. Lack of explicit linguistic clues as to how the evidential information is to be metarepresented may raise inferencing demands children are not up to yet. Particularly for evidential adverbials (certainly, possibly, evidently) or impersonal constructions (it seems that), children may be confused about who to attribute evidential information to without any explicit linguistic guidance (in the form of pronouns, proper names, inflectional suffixes or morphemes, prepositional phrases): 'is it certain according to the story-character ...?', 'is it certain according to the narrator/writer ... ?', 'is it certain according to the experimenter ...?'. The missing information-giving bound or free morphological marking fails to guide children to an overall consistent interpretation. Secondly, (9) involves three levels of representation, yet children seem to have successfully interpreted it does not seem that as a weakening evidential marker. As already 
suggested, the literal meaning of fenete $=$ 'can be seen', and particularly, the negative de fenete $=$ 'cannot be seen', in Modern Greek might have led children to correctly consider it as a weakening marker on the assumption that 'what cannot be seen, cannot be evidenced with a strengthened degree of certainty'.

Results obtained from primary school children indicated little improvement for the $1^{\text {st }}$ and $2^{\text {nd }}$ graders. Evidential understanding seemed to level off at the $4^{\text {th }}$ grade while peaking at the $6^{\text {th }}$ grade (Graphs $1,2,3$ ).

Evidential
\begin{tabular}{|l|l|l|l|}
\hline I think & Linguistic task & \multicolumn{1}{c}{$\times$} \\
\hline it seemed to me & 1 & $70,43 \%$ & $29,57 \%$ \\
\hline she thinks & 2 & $42,8 \%$ & $57,1 \%$ \\
\hline it seems that & 3 & $57,1 \%$ & $42,8 \%$ \\
\hline I think & 4 & $33,33 \%$ & $66,66 \%$ \\
\hline it doesn't seem that & 5 & $73,56 \%$ & $26,44 \%$ \\
\hline I suppose & 6 & $52,3 \%$ & $47,6 \%$ \\
\hline evidently & 7 & $47,6 \%$ & $52,3 \%$ \\
\hline I think & 8 & $28,57 \%$ & $71,42 \%$ \\
\hline Possibly & 9 & $76,19 \%$ & $23,81 \%$ \\
\hline I think (literary) & 10 & $9,52 \%$ & $90,47 \%$ \\
\hline Certainly & 11 & $57,1 \%$ & $42,8 \%$ \\
\hline Tab & 12 & $19,04 \%$ & $80,95 \%$ \\
\hline
\end{tabular}

Table 6: Percentages of evidential interpretation by $\mathbf{1}^{\text {st }}$ graders/6-7 year-old passers $(\sqrt{ })$ and failers $(X)$. Number of subjects: 21.

\begin{tabular}{|l|l|l|l|}
\multicolumn{4}{|c|}{ I } \\
\hline Ithink & 1 & $76,43 \%$ & $23,57 \%$ \\
\hline it seemed to me & 2 & $62,5 \%$ & $37,5 \%$ \\
\hline she thinks & 3 & $84,37 \%$ & $15,62 \%$ \\
\hline it seems that & 4 & $34,37 \%$ & $65,62 \%$ \\
\hline I think & 5 & $83,98 \%$ & $16,02 \%$ \\
\hline it doesn't seem that & 6 & $40,62 \%$ & $59,37 \%$ \\
\hline I suppose & 7 & $37,5 \%$ & $62,5 \%$ \\
\hline Evidently & 8 & $28,12 \%$ & $71,87 \%$ \\
\hline I think & 9 & $71,87 \%$ & $28,12 \%$ \\
\hline Possibly & 9 & $37,5 \%$ & $62,5 \%$ \\
\hline I think (literary) & 10 & $53,12 \%$ & $46,87 \%$ \\
\hline Certainly & 11 & $68,75 \%$ & $31,25 \%$ \\
\hline
\end{tabular}

Table 7: Percentages of evidential interpretation by $\mathbf{2}^{\text {nd }}$ graders/7-8 year-old passers $(\sqrt{ })$ and failers $(\mathbf{X})$. Number of subjects: $\mathbf{3 2}$.

\begin{tabular}{|c|c|c|c|}
\hline & & 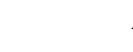 & $>$ \\
\hline I think & 1 & $73,01 \%$ & $26,99 \%$ \\
\hline it seemed to me & 2 & $65,57 \%$ & $34,42 \%$ \\
\hline she thinks & 3 & $91,80 \%$ & $8,19 \%$ \\
\hline it seems that & 4 & $52,45 \%$ & $47,54 \%$ \\
\hline I think & 5 & $55,73 \%$ & $44,26 \%$ \\
\hline it doesn't seem that & 6 & $44,26 \%$ & $55,73 \%$ \\
\hline I suppose & 7 & $63,93 \%$ & $36,06 \%$ \\
\hline Evidently & 8 & $31,14 \%$ & $68,85 \%$ \\
\hline I think & 9 & $70,49 \%$ & $29,50 \%$ \\
\hline Possibly & 10 & $54,09 \%$ & $45,90 \%$ \\
\hline I think (literary) & 11 & $49,18 \%$ & $50,81 \%$ \\
\hline Certainly & 12 & $68,85 \%$ & $31,14 \%$ \\
\hline
\end{tabular}

Table 8: Percentages of evidential interpretation by $\mathbf{3}^{\text {rd }}$ graders/8-9 year-old passers $(\sqrt{ })$ and failers $(\boldsymbol{X})$. 
Number of subjects: 61.

\begin{tabular}{|l|l|l|l|}
\multicolumn{2}{|c|}{ } \\
\hline I think & 1 & $83,78 \%$ & $16,21 \%$ \\
\hline it seemed to me & 2 & $81,08 \%$ & $18,91 \%$ \\
\hline she thinks & 3 & $89,18 \%$ & $10,81 \%$ \\
\hline it seems that & 4 & $72,97 \%$ & $27,02 \%$ \\
\hline I think & 5 & $72,97 \%$ & $27,02 \%$ \\
\hline it doesn't seem that & 6 & $70,27 \%$ & $29,72 \%$ \\
\hline I suppose & 7 & $75,67 \%$ & $24,32 \%$ \\
\hline Evidently & $7 \%$ & $62,16 \%$ & $37,83 \%$ \\
\hline I think & 8 & $81,08 \%$ & $18,91 \%$ \\
\hline Possibly & 9 & $64,86 \%$ & $35,13 \%$ \\
\hline I think (literary) & 10 & $67,56 \%$ & $32,43 \%$ \\
\hline Certainly & 11 & $81,08 \%$ & $18,91 \%$ \\
\hline
\end{tabular}

Table 9: Percentages of evidential interpretation by $4^{\text {th }}$ graders/9-10 year-old passers $(\sqrt{ })$ and failers $(\mathbf{X})$. Number of subjects: 37.

\begin{tabular}{|c|c|c|c|}
\hline & & 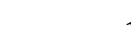 & $x$ \\
\hline I think & 1 & $87,43 \%$ & $12,57 \%$ \\
\hline it seemed to me & 2 & $82,33 \%$ & $17,67 \%$ \\
\hline she thinks & 3 & $83,21 \%$ & $16,79 \%$ \\
\hline it seems that & 4 & $77,28 \%$ & $22,72 \%$ \\
\hline I think & 5 & $63,04 \%$ & $36,95 \%$ \\
\hline it doesn't seem that & 6 & $67,39 \%$ & $32,60 \%$ \\
\hline I suppose & 7 & $71,73 \%$ & $28,26 \%$ \\
\hline Evidently & 8 & $32,60 \%$ & $67,39 \%$ \\
\hline I think & 9 & $84,78 \%$ & $15,21 \%$ \\
\hline Possibly & 10 & $71,73 \%$ & $28,26 \%$ \\
\hline I think (literary) & 11 & $67,39 \%$ & $32,60 \%$ \\
\hline Certainly & 12 & $86,95 \%$ & $13,04 \%$ \\
\hline
\end{tabular}

Table 10: Percentages of evidential interpretation by $\mathbf{5}^{\text {th }}$ graders/10-11 year-old passers $(\sqrt{ })$ and failers $(\mathbf{X})$. Number of subjects: 46.

\begin{tabular}{|l|l|l|l|}
\multicolumn{2}{|c|}{ V } \\
\hline I think & 1 & $94,12 \%$ & $5,88 \%$ \\
\hline it seemed to me & 2 & $89,66 \%$ & $10,34 \%$ \\
\hline she thinks & 3 & $88,47 \%$ & $11,53 \%$ \\
\hline it seems that & 4 & $76,28 \%$ & $23,72 \%$ \\
\hline I think & 5 & $77,35 \%$ & $12,64 \%$ \\
\hline it doesn't seem that & 5 & $90,56 \%$ & $9,43 \%$ \\
\hline I suppose & 6 & $90,56 \%$ & $9,43 \%$ \\
\hline Evidently & 7 & $60,37 \%$ & $39,62 \%$ \\
\hline I think & 8 & $92,45 \%$ & $7,54 \%$ \\
\hline Possibly & 9 & $77,35 \%$ & $22,64 \%$ \\
\hline I think (literary) & 10 & $77,35 \%$ & 22,64 \\
\hline Certainly & 11 & $88,67 \%$ & $11,32 \%$ \\
\hline
\end{tabular}

Table 11: Percentages of evidential interpretation by $6^{\text {th }}$ graders/11-12 year-old passers $(\sqrt{ })$ and failers $(X)$. Number of subjects: 53. 


\begin{tabular}{|l|l|l|}
\hline Succeeding in interpreting & I think & $80,86 \%$ \\
\hline & she thinks & $82,35 \%$ \\
\hline & it seemed to me & $70,65 \%$ \\
\hline & I suppose & $64,49 \%$ \\
\hline & I ween & $61,95 \%$ \\
\hline & it does not seem that & $60,9 \%$ \\
\hline Failing in interpreting & it seems that & $57,78 \%$ \\
\hline & evidently, possibly, certainly & $53,96 \%$ \\
\hline
\end{tabular}

Table 12: Mean percentages of tested evidentials in descending order of successful interpretation by primary school children. Number of subjects: $\mathbf{2 5 0}$.

Comparing the mean scores for pre-school children (Table 4) with mean results obtained from primary school children (Table 12), it is observed that top-scoring and bottom-scoring evidential items remain constant (I think vs. it seems that, evidently, possibly, certainly). In-between evidentials have been slightly reordered in terms of scoring percentages. Worth mentioning is how results for $3^{\text {rd }}$ person think and it doesn't seem that have been reversed. Primary school children exhibit improved understanding of $3^{\text {rd }}$ person think and a poorer understanding of it doesn't seem that. This confirms the reservations expressed earlier about preschoolers' successful interpretation of it doesn't seem that being a side-effect of its semantic meaning in Modern Greek rather than a genuine indication of correct evidential interpretation. Overall, the results (Graphs 1, 2, 3 ) confirm the long period of gradually developing evidential vocabulary. Moreover, they suggest a variation among the developmental trajectories of evidential verbs, the syntactically more complex construction it seems that/to me and adverbials, where verbs seem to be the first and easier to be acquired with through-age higher scores (Graph 1) and adverbials the last and more demanding with early-age low scores and a sharp rise around 6/7 years of age, peaking at 11/12 years of age (Graph 3). It seems that/to me exhibits a through-age moderate but relatively steady competence with an upward trend, peaking at 9-12 years of age (Graph 2). The question is how can so graded an acquisition be explained?

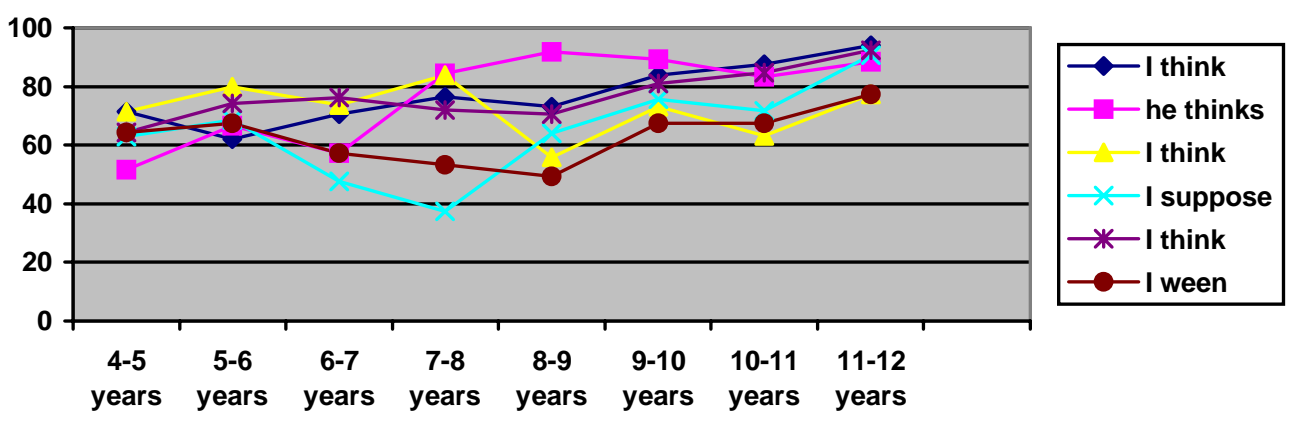

Graph 1: Developmental trend for understanding of evidential verbs for 4-12 year-olds 


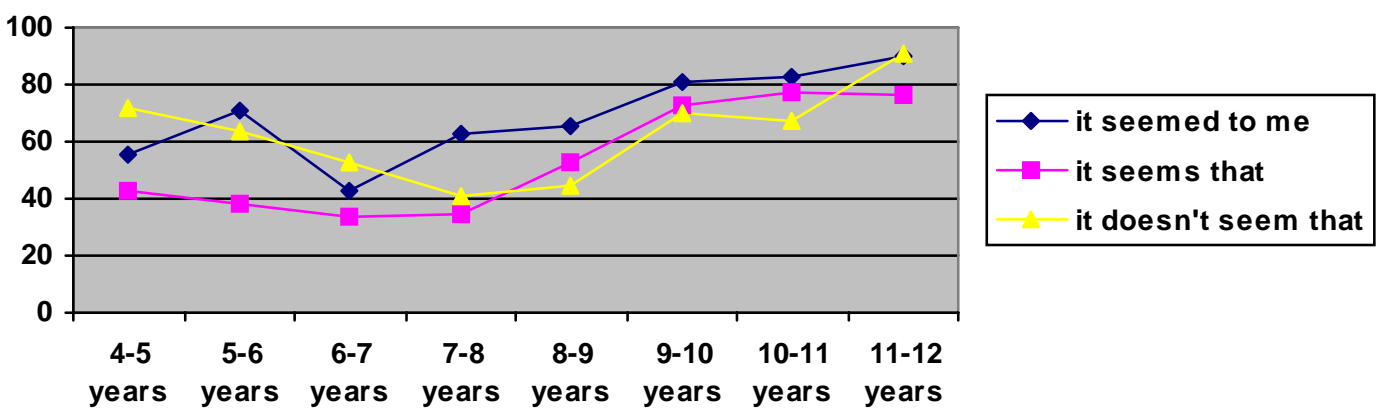

Graph 2: Developmental trend for understanding of evidential construction it seems that/to me for 4-12 year-olds

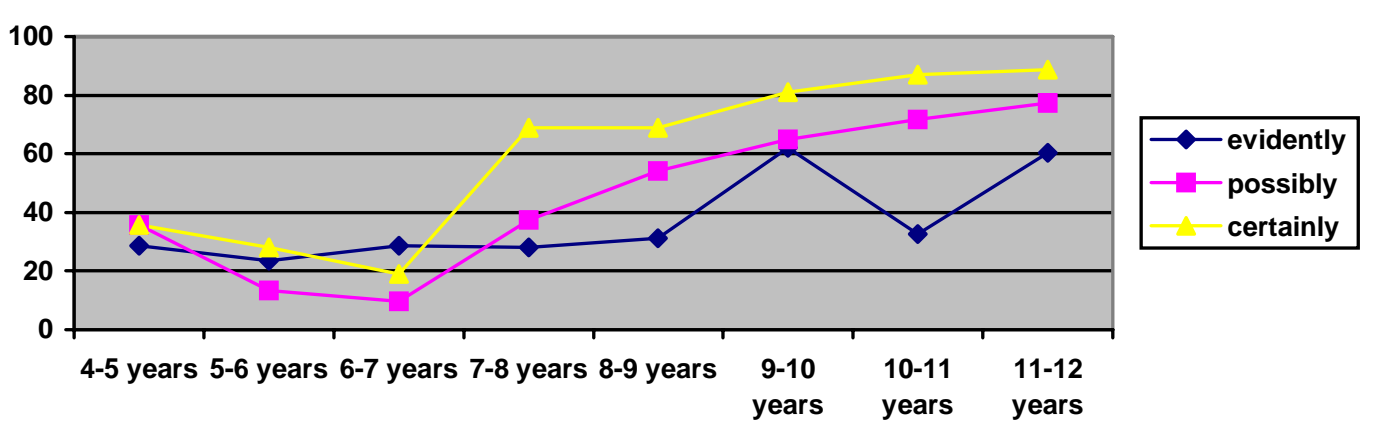

Graph 3: Developmental trend for understanding of evidential adverbials for 4-12 year-olds

\subsection{Interpreting the evidence}

One way to explain the findings is to associate the development of $4 ; 6-11 ; 7$ children's sequential understanding of evidentials (Tables 4 and 12) with ordered layers of metarepresentation (Sperber 1994; Wilson 2000, 2005). In this framework, the order of acquisition sketched in Tables 4 and 12 is predicted by Sperber's three levels of metarepresentational sophistication.

Sperber (1994) described three stages in pragmatic development which correlate with stages in the development of metarepresentational skills. Each stage is determined by one interpretation strategy that the hearer may employ: A naively optimistic, a cautiously optimistic and a sophisticated strategy, with successive stages (and respective strategies) growing in sophistication. Next I will show how the stages I have sketched in my data run parallel to Sperber's strategies and enable speakers and hearers to become increasingly more competent communicators.

A naively optimistic speaker is benevolent and competent enough to realize what is relevant and salient for her hearer at the time. A naively optimistic hearer looks for an interpretation that seems relevant enough, and as long as he finds one, he assumes this is the speaker's meaning; if he does not, he can reason no further, and communication will fail. If I tell my 3;6 year old son:

Your sister is in your room. 
he will be able to interpret my utterance in a number of ways: Your sister is hiding from you, your sister is looking for you, your sister is meddling with your bike. As long as the first interpretation my son retrieves is relevant enough, it is the intended one, and I have spoken competently; as long as the first interpretation my son retrieves not only seems relevant but is genuinely so (e.g. I have not been lying or trying to distract him from something happening elsewhere) I have spoken benevolently too. As Wilson points out:

A Naively Optimistic hearer has no need to think about the speaker's mental states in order to identify her meaning: the only time he needs to represent the speaker's thoughts is when, having found an acceptable interpretation, he concludes that it is the intended one. (Wilson 2005: 391).

There is little need to think about the speaker's mental states, because as Sperber points out, naively optimistic children

easily believe that one is talking about what happens to be foremost on their mind (and conversely that what they want to talk about is foremost in the minds of their listeners). (Sperber 1994: 191).

A cautiously optimistic speaker is benevolent, but not necessarily competent. A cautiously optimistic hearer is capable of avoiding misunderstandings by rejecting the first interpretation he finds relevant enough and by asking himself on what interpretation the speaker might have thought her utterance would be relevant enough to him. Suppose I say (12) knowing that Sophia is willing to play with her younger brother. (12) might be accidentally relevant if my son, who had a row with his sister over who will ride the bike, finds the first relevant enough interpretation to be the one on which I am saying that his sister is meddling with his bike. A naively optimistic hearer would accept this as the intended interpretation. A cautiously optimistic hearer would be able to consider whether I could have expected my utterance, on this interpretation, to be relevant enough to him. An utterance may also be accidentally irrelevant. To use Deirdre Wilson's example (2005: 392), if on asking my son to bring me the book on the kitchen table, he finds no book on the kitchen table, there are two alternatives: If he is a naively optimistic hearer, he will not look beyond the linguistically encoded meaning, he will fail in finding an acceptable interpretation and communication will fail. If he is a cautiously optimistic hearer, he will ask himself which book I might have thought was on the kitchen table and he will succeed in identifying the intended interpretation by bringing me the book lying near the table on the floor. In other words, a cautiously optimistic communicator can distinguish others' false beliefs (here, my wrong assumption that the book is on the kitchen table) from his own beliefs and reality (here, the fact that the book is on the floor).

A sophisticated speaker can successfully engage herself in complex full-fledged communicative patterns, such as deception, hearsay, irony. In deception, for example, she may be trying to mislead the hearer by intending an interpretation to seem relevant enough without being so. A sophisticated hearer must retrieve the interpretation that the speaker might have thought would seem relevant enough to him. In (12), the mother may be trying to distract her child from something else. If capable of using the strategy of sophisticated understanding, the child may identify his mother's meaning on which she might have thought he would think her utterance was relevant enough and as a consequence, he will not get deceived. In hearsay, a sophisticated speaker may be 
reporting on others' beliefs about others' beliefs that differ from his own. A sophisticated hearer should be able to identify the speaker's attributing others' beliefs to others' and her dissociative attitude to the attributed beliefs.

The move from naive optimism to cautious optimism marks the acquisition of firstorder theory of mind, i.e. the ability to attribute to others beliefs that differ from our own. The move from cautious optimism to sophisticated understanding marks the acquisition of second-order theory of mind, i.e. the ability to attribute to others beliefs about the beliefs of others that differ from our own (Wilson 2000, 2005). As a consequence, this framework predicts that a naively optimistic child would be able to interpret evidentials along the lines of $(1-6)$ and (8) (Table 5), because these encode the speaker's complying belief with others' beliefs. A cautiously optimistic child would be able to interpret evidentials along the lines of (7), because this encodes the writer's dissociative belief about Efi's belief (that she knows). Having mastered sophisticated understanding, a child would be able to interpret evidentials along the lines of (9), (10) and (11), because these encode others' beliefs about the beliefs of others that differ from her own. In (9), the child should be able to interpret father-elephant's dissociative belief regarding his wife's belief (that elephants can lose weight through dieting). In (10), the child should be able to interpret Eimy's dissociative belief regarding Bananas' belief (that they have made a slide). In (11), the child should be able to interpret Loulou's dissociative belief regarding Bananas' belief (that they have made a slide). Generally, in the third, sophisticated strategy, the child would be able to interpret evidentials relying on complex dissociative hearsay, irony and deceiptful pretence, by encoding (and interpreting) the beliefs of others about the beliefs of others that differ from her own, as in (13), (14) and (15):

(13) Allegedly/apparently, the little polar bear was drifted along by the storm. (adapted from Little polar bear)

(14) Mr Wolf was well-meant, supposedly!

(adapted from The little red-riding hood)

(15) The cat's master was supposedly drowning. (adapted from Puss in boots)

In (13), hearsay information is reported by a speaker who is dissociating himself from the writer's belief about father-bear's belief regarding the little bear lost in the storm (who had in fact safely reached the South Pole). In (14), the speaker is ironically implying that the wolf was not well-meant, by dissociating himself from the writer's belief about the wolf's benevolent thoughts regarding Red Riding Hood. In (15), the speaker is able to identify the cat's master intention to deceive by pretending to be drowning.

Such pragmatically complex evidential items are only acquired once children have mastered the strategy of sophisticated understanding. In this direction, it has been shown (Ifantidou 2005a, 2005b) that two hearsay particles in Modern Greek, (taha, dithen), are not fully acquired until late primary school years because they rely on complex metarepresentational reasoning, i.e. on ironical hearsay interpretation. This is predicted by Sperber's strategy of sophisticated understanding which coincides with "fully-fledged communicative competence" involving irony and multi-layered hearsay (Sperber 1994: 197). On co-interpreting previous findings on taha/dithen (Ifantidou 2005a, 2005b) with results obtained in this study, a number of interesting observations can be made. First, syntactically more complex evidentials, such as it seems that/to me, 
are acquired earlier than syntactically less complex evidentials, such as taha/dithen (Introduction, footnotes 3 and 4). Secondly, the semantically/stylistically marked ween is appropriately interpreted by preschoolers similarly to unmarked think or highly infrequent suppose. Thirdly, the pragmatically simpler think is acquired earlier than the pragmatically sophisticated taha/dithen (footnote 5) and earlier than the pragmatically ambiguous adverbials (section 3.2). These findings may be indications as to what guides the development of evidentials, suggesting that syntactic or semantic/stylistic sophistication does not affect the acquisition process to the extent that pragmatic complexity does. This is explained in Sperber's framework, where as the child develops from naive optimism to cautious optimism to sophisticated understanding, she is progressively able to retrieve extra levels of metarepresentation and as a consequence, cope with evidentials of increasing pragmatic and cognitive complexity.

\section{Conclusions}

In this study, I have suggested that the acquisition of the evidential lexicon in Modern Greek is firstly, extended (in time of development) and secondly, ordered (in sequence of development). More importantly, I hope to have shown that both time and order of acquisition are cognitively-driven. Sperber's framework on how pragmatic abilities draw on developing mind-reading abilities helps explain how evidentials follow a 3stage pattern of growing pragmatic and cognitive complexity. In the first stage, evidential items are easily and early acquired because the metarepresentational reasoning required is least complex as determined by the naively optimistic strategy (approximately 2-4-5 year-olds). In the second stage, evidential items are later and less easily acquired because the metarepresentational reasoning required is more complex as determined by the cautiously optimistic strategy (approximately $4-7$ year olds). In the final stage, evidential items are later still and more effortfully acquired because the metarepresentational reasoning required is most complex as determined by the strategy of sophisticated understanding (approximately $7-12$ year olds). Follow-up work, for example, on negative evidential items - I don't suppose, I don't think, it doesn't sound, it can't be true - or other less common types of evidentials - I suspect, I conclude, I predict, I wonder, allegedly, apparently - may reveal further interesting links with Sperber's interpretation strategies.

\section{References}

Abbeduto, L., \& S. Rosenberg (1985) Children's knowledge of the presuppositions of know and other cognitive verbs. Journal of Child Language 12: 621-641.

Aksu-Koç, A. (1988) The Acquisition of Aspect and Modality: The Case of Past Reference in Turkish. Cambridge: Cambridge University Press.

Astington, J.W., \& J.M. Jenkins (1995) Theory of mind development and social understanding. Cognition and Emotion 9: 151-165.

Bascelli, E., \& M.S. Barbieri (2002) Italian children's understanding of the epistemic and deontic modal verbs dovere (must) and potere (may). Journal of Child Language 29: 87-107. 
Bassano, D. (1983) Five-year-olds' understanding of 'savoir' and 'croire'. Journal of Child Language 12: 621-641.

Bloom, L., M. Rispoli, B. Gartner, \& J. Hafitz (1988) Acquisition of complementation. Journal of Child Language 16: 101-120.

Booth, J., \& W. Hall (1995) Development of the understanding of the polysemous meanings of the mental-state verb know. Cognitive Development 10: 529-549.

Bretherton, I., \& M. Beeghly (1982) Talking about internal states: The acquisition of an explicit theory of mind. Developmental Psychology 18: 906-921.

Byrnes, J.P., \& M.A. Duff (1989) Young children's comprehension of modal expressions. Cognitive Development 4: 369-387.

Choi, S. (1995) The development of epistemic sentence-ending modal forms and functions in Korean children. In J. Bybee \& S. Fleischman (eds.), Modality in Grammar and Discourse. Amsterdam: Benjamins Publishing Company, pp. 165-204.

Coates, J. (1988) The acquisition of the meanings of modality in children aged eight and twelve. Journal of Child Language 15: 425-434.

Frank, R., \& W. Hall (1991) Polysemy and the acquisition of the cognitive internal state lexicon. Journal of Psycholinguistic Research 20: 283-304.

Hirst, W., \& J. Weil (1982) Acquisition of epistemic and deontic meaning of modals. Journal of Child Language 9: 659-666.

Ifantidou, E. (2001) Evidentials and Relevance. Amsterdam and Philadelphia: John Benjamins Publishing Company.

Ifantidou, E. (2005a) Hearsay devices and metarepresentation. In S. Marmaridou, E. Antonopoulou, and V. Nikiforidou (eds.), Reviewing Linguistic thought: Converging Trends in the $21^{\text {st }}$ century. Berlin, New York: Mouton de Gruyter, pp. 401-418.

Ifantidou, E. (2005b) Evidential particles and mind-reading. Pragmatics and Cognition 13: 253-295.

Ifantidou, E. (2005c) Evidentials and metarepresentation. Paper delivered at the $9^{\text {th }} \operatorname{IPrA}$ Conference, Riva del Garda, Italy. (to appear) in C. Paradis and L. Ekberg (eds.), Functions of Language, Special Issue on 'Evidentiality: Theoretical and applied'. Amsterdam/Philadelphia: John Benjamins Publishing Company.

Johnson, C., \& M. Maratsos (1977) Early comprehension of mental verbs: Think and know. Child Development 48: 1743-1747.

Johnson, C.N., \& H.M. Wellman (1980) Children's developing understanding of mental verbs: Remember, know and guess. Child Development 51: 1095-1102.

Miscione, J.R., R. Marvin, O’Brien, \& M. Greenberg (1978) A developmental study of preschool children's understanding of the words "know" and "guess". Child Development 49: 1107-1113.

Moore, C., D. Bryant, \& D. Furrow (1989) Mental terms and the development of certainty. Child Development 60: 167-171.

Moore, C., \& J. Davidge (1989) The development of mental terms: Pragmatics or semantics? Journal of Child Language 16: 633-641. 
Moore, C., K. Pure, \& D. Furrow (1990) Children's understanding of the modal expression of speaker certainty and uncertainty and its relation to the development of a representational theory of mind. Child Development 61: 722-730.

Noveck, I., S. Ho, \& M. Sera (1996) Children's understanding of epistemic modals. Journal of Child Language 23: 621-643.

Papafragou, A. (1998) The acquisition of modality: Implications for theories of semantic representation. Mind \& Language 13: 370-399.

Papafragou, A. (2001) Linguistic early linguistic and conceptual capacities: The role of a theory of mind. In A. Cienki, B. Luka \& M. Smith (eds.), Conceptual and Discourse Factors in Linguistic Structure. Stanford: CSLI Publications, pp. 169-184.

Perkins, M.R. (1983) Modal Expressions in English. London: Frances Pinter.

Piéraut-Le Bonniec, G. (1980) The Development of Modal Reasoning. Genesis of Necessity and Possibility Notions. New York: Academic Press.

Schwanenflugel, P., W. Fabricius, \& C. Noyes (1996) Developing organization of mental verbs: Evidence for the development of a constructivist theory of mind in middle childhood. Cognitive Development 11: 265-294.

Shatz, M., H. Wellman, \& S. Silber (1983) The acquisition of mental terms: A systematic investigation of the first reference to mental states. Cognition 14: 301-321.

Smoczynksa, M. (1993) The acquisition of polish modal verbs. In N. Dittmar \& A. Reich (eds.), Modality in Language Acquisition. Berlin: de Gruyter, pp. 145-169.

Sperber, D. (1994) Understanding verbal understanding. In J. Khalfa (ed.), What is Intelligence? Cambridge: Cambridge University Press.

Stephany, U. (1986) Modality. In P. Fletcher \& M. Garman (eds.), Language Acquisition: Studies in First Language Development. Cambridge: Cambridge University Press, pp. 375-400.

Wells, G. (1985) Language Development in the Pre-school Years. Cambridge University Press.

Wilson, D. (2000) Metarepresentation in linguistic communication. In D. Sperber (ed.), Metarepresentations. Oxford, New York: Oxford University Press, pp. 411-448.

Wilson, D. (2005) New directions for research in pragmatics and modularity. In S. Marmaridou, E. Antonopoulou, and V. Nikiforidou (eds.), Reviewing Linguistic thought: Converging Trends in the $21^{\text {st }}$ century. Berlin, New York: Mouton de Gruyter, pp. 375-400.

\section{Appendix}

The linguistic tasks, the question format, correct answers (underlined) for the twelve evidential items tested and references for children's readers.

\section{Linguistic task 1}

(DRAWING: Little mouse staring at his reflection in the mirror, fixing his bow tie) 
Little mouse admired himself at the mirror and said:

"I am so smart!"

"What did little mouse say he is, Banana 1?" Banana 2 asked.

"I think he said he is a cart, Banana 2!" Banana 1 said.

What is the meaning of I think?

Banana 1:

A. is not certain that the little mouse said cart.

B. knows and is certain that the little mouse said cart.

C. ............. (other)

\section{Linguistic task 2}

The rabbit and the ferret were taking a walk to the woods, when they saw, terrified, a huge bear getting close. The ferret climbed up a tree nearby.

(DRAWING: The rabbit lying on the ground, pretending to be dead, the bear sniffing onto his face)

After the bear left, the ferret came down the tree and asked the rabbit:

"It seemed to me that I saw the bear whispering at your ear. What was he saying?"

What does the ferret mean by saying it seemed to me?

A. I am certain, I saw the bear whispering to you.

B. I am not sure the bear was whispering to you or not.

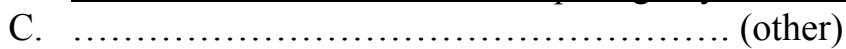

\section{Linguistic task 3}

It is Sarah's birthday. She is now opening her presents with the other kids. But none of them can guess what is in the big packet. Efi thinks she knows. Do you?

(DRAWING: Sarah and her friends sitting on the floor among presents, trying to open them up)

When Sarah 'thinks she knows':
A. ................... (other)
B. knows and is certain about what there is in the box.
C. has doubts about what is in the box.

\section{Linguistic task 4}

The baby is the first to get to the swimming pool.

(DRAWING: A swimming pool, a toy-boat floating, the baby crawling, and five older kids running after him)

It seems that the baby likes Sarah's new toy-boat floating in the pool. 
Do you understand it seems that as:

A. maybe (I can tell from his eagerness to get there) the baby likes Sarah's new toy-boat.

B. it is definite that the baby likes Sarah's new toy boat.

C............$($ other)

\section{Linguistic task 5}

The two bananas tried again and again to assemble their new slide but they could not quite make it. This is what they made instead.

(DRAWING: The two bananas sitting on a roughly made, funny type of bed)

Tired, after many fails, they said:

B2: "Are you thinking what I am thinking Banana 1?"

B1: "I think I do Banana 2. Time to sleep!"
A. B1 imagines but is not certain that Bs wants to go to bed.
B. B1 is certain that $\mathrm{B} 2$ wants to go to bed.
C. $\ldots \ldots \ldots \ldots \ldots$........ (other)

\section{Linguistic task 6}

(DRAWING: In the bathroom, father-elephant on the scales staring down on the weight measurement, the rest of the family standing around him)

Being forced to diet for many days by his wife, to live on healthy food and exercise, $\mathrm{Mr}$ Elephant said:

"It doesn't seem that we have lost any weight, dear!"

"Maybe elephants have to be fat", said Louki.

"Nonsense!" Mrs Elephant said. "We must not give up now".

By saying it does not seem that ..., Mr Elephant means that
A. (other)
B. he is certain that they have not lost any weight.
C. may be they have lost a bit of weight, but so little that it's not worth it.

\section{Linguistic task 7}

(DRAWING: King Snail standing on an ancient ruin-column of Parthenon, talking to Pinnochio)

Pinnochio travelled from his country Italy to Greece to find a strange cyclamen growing in Athens. His adventures begin in Akropolis, where he meets King Snail.

"May I take you on a tour to the ruins of Akropolis?" said he in a formal tone "It is your first visit, I suppose, in Athens" 
Do you understand I suppose as:

King Snail

A. knows and is certain that it is Pinnochio's first visit in Athens.

B. $\ldots . . . \ldots \ldots \ldots$ (other)

C. imagines and is not certain that it is Pinnochio's first visit in Athens.

\section{Linguistic task 8}

The two bananas tried again and again to assemble their new slide but they could not quite make it. This is what they made instead.

(DRAWING: The two bananas sitting on a roughly made, quite odd type of see-saw)

At that point, Eimy showed up.

"What's this?" she asked.

"It's a fix-it-yourself slide", Banana 2 said. "We fixed it ourselves twice ..."

"But it still does not look like a slide", Banana 2 said.

"Well. Evidently it does not look like a slide, it's more like a see saw" Eimy said.

Do you understand the word evidently as:
A. .................. (other)
B. it is obvious that what you made does not look like a slide.
C. it is doubtful whether what you made does not look like a slide.

\section{Linguistic task 9}

(DRAWING: The statue of a poet, letters of the alphabet and words flowing from his hands down onto Pinnochio, who is lying at the statue's foot)

It got dark and Pinnochio felt so tired. He looked around, further down there was the statue of Odisseas Elitis. With one leap he settled at his feet.

"Mr poet, I feel cold"

And the poet leaned over and gently covered him with two of his poems.

"My eyes are heavy, Mr poet. I think I am falling asleep.

When Pinnochio says I think ..., he:

A. knows and is certain that he is falling asleep.

B. feels and is not quite certain that he is falling asleep.

C. $\ldots . . . \ldots \ldots \ldots$ (other)

\section{Linguistic task 10}

The two bananas tried again and again to assemble their new slide but they could not quite make it. This is what they made instead.

(DRAWING: The two bananas sitting on a roughly made bed)

At that point, Loulou showed up.

"What's this?" she asked.

"It's a fix-it-yourself slide", Banana 2 said. "We fixed it ourselves twice ..."

"But it still does not look like a slide", Banana 2 said. 
"Well. You possibly made a bed" Eimy said.

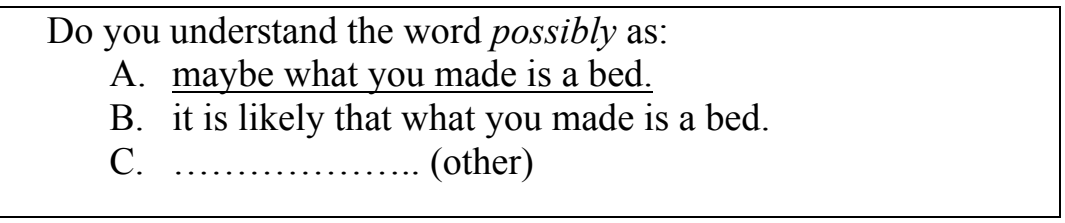

\section{Linguistic task 11}

(DRAWING: In a garden, many snails in a row, waving Greek flags, followed by Little mouse, all heading for Pinnochio)

All the snails in the National Gardens heard about the strange cyclamen Pinnochio was looking for, but no one had neither seen it nor heard of it. They were so sorry - what could they do they would disappoint him, but to soothe his sorrow, they would offer him candies and sweetsmelling cinnamon biscuits. Little mouse is getting closer to the sweets.

"I am ashamed to admit it, but you see, my mouth waters. Can I get a candy?" he asked impatiently.

"The sweets are for Pinnochio" snail Gary explained, "but I ween they are enough for you and fifty more clockwork mice to eat".

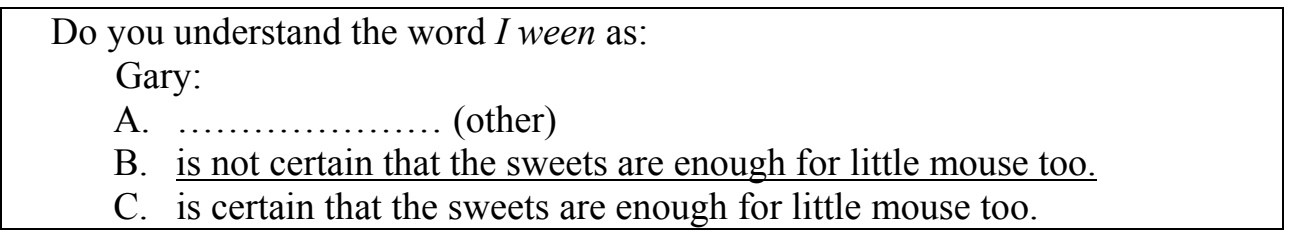

\section{Linguistic task 12}

(DRAWING: A boat, with two triangular sails)

The triangle has, certainly, three angles.

The word certainly means:

A. it is definite that the triangle has three angles.

B. ............. (other)

C. it is safe that the triangle has three angles.

\section{References}

Boulotis, C. (2001) Pinnochio in Athens. Athens: Ellinika Grammata.

Busquets, C. (1995) (translated by M. Tsigagou) The two friends. Haidari: Iliotropio.

Hopkinson Simon, \& Paul Pattie (1998) Bananas in pyjamas. A wonderful toy (translated by R.

Rossi-Zairi). Athens: Ellinika Grammata.

Murphy, J. (1989) A piece of cake (translated by R.R. Rossi-Zairi). Athens: Rossis. 
394 Elly Ifantidou

Petty, K., \& L. Kopper (1998) What's that shape? (translated by G. Pateraki). Athens: Minoas.

Pierre-Marie Valat (1996) Les formes (translated by T. Petrakis). Athens: Delithanasis.

Tulloch, R., \& L. Worthington (1998) Bananas in pyjamas. Invitation to dinner (translated by R. Rossi-Zairi). Athens: Ellinika Grammata. 